\title{
THE INFLUENCE OF ADVANCE LETTERS ON RESPONSE IN TELEPHONE SURVEYS A META-ANALYSIS
}

\author{
EDITH DE LEEUW \\ MARIO CALLEGARO \\ JOOP HOX \\ ELLY KORENDIJK \\ GERTY LENSVELT-MULDERS
}

\begin{abstract}
Recently, the leading position of telephone surveys as the major mode of data collection has been challenged. Telephone surveys suffer from a growing nonresponse, partly due to the general nonresponse trend for all surveys and partly due to changes in society and technology influencing contactability and willingness to answer. One way to counteract the increasing nonresponse is the use of an advance letter. In mail and face-to-face surveys, advance letters have been proven effective. Based on the proven effectiveness in face-to-face and mail surveys, survey handbooks advise the use of advance letters in telephone surveys. This study reviews the evidence for this advice and presents a quantitative summary of empirical studies on the effectiveness of advance letters in raising the response rate for telephone surveys. The major conclusion is that advance letters are also an effective tool in telephone surveys, with an average increase in response rate (RR1) from 58 percent (no letter) to 66 percent (advance letter), and an average increase in cooperation rate (COOP1) from 64 percent (no letter) to 75 percent (advance letter).
\end{abstract}

Telephone surveys have become more and more popular in the last 30 years, reaching their zenith in the 1990s. At the end of the twentieth century, telephone interviews were the major mode of data collection for surveys of households, individuals, and establishments in North America, Canada, Australia, and parts

EDITH DE LEEUW, JOOP HOX, ELLY KORENDIJK AND GERTY LENSVELT-MULDERS are with the Department of Methodology and Statistics, Utrecht University, Heidelberglaan 1, 3508 TC Utrecht, The Netherlands. mario Callegaro is with the University of Nebraska, Lincoln, Program in Survey Research and Methodology, 200 N. 11th Street, 4th Floor, Lincoln, NE 68508, USA. Address correspondence to Mario Callegaro; e-mail: mario.callegaro@gmail.com 
of Western Europe (Nathan 2001). Recently, the leading position of telephone surveys has been challenged. Telephone surveys suffer from an increasing nonresponse (Massey, O'Connor, and Krotki 1997; Steeh et al. 2001), partly due to the general nonresponse trends (De Leeuw and de Heer 2002) and partly due to changes in communication technology influencing the contactability by phone (Dillman 2002).

Past research on reducing nonresponse in telephone surveys has focused on both interviewer-dependent and interviewer-independent measures. Interviewer vocal characteristics (Oksenberg and Cannell 1988; Groves et al. 2006), interviewer tactics and persuasion strategies (Hox, De Leeuw, and Snijkers 1998; Pondman 1998; Dijkstra and Smith 2002; De Leeuw and Hox 2004), and interviewer training (Groves and McGonagle 2001) all influence the response in telephone surveys and can be used to raise response rates. An interviewerindependent measure that has been successful in raising response is the use of incentives; for an overview, see Singer (2002) and Cantor, O'Hare, and O'Connor (2006). Less clear is the evidence regarding advance letters.

Meta-analysis has shown that increasing the number of contacts has been very effective in raising response rates in mail surveys, with advance letters as effective as an additional full contact (Heberlein and Baumgartner 1978; Heberlein and Baumgartner 1981; Dillman 2000). Advance letters are also used in face-to-face surveys, and many large statistical agencies use advance letters as a standard procedure in their major surveys (Luppes 1995; Groves and Couper 1998; White et al. 1998). One reason is that interviewers value an advance letter; they gain professional confidence from it (Groves and Snowden 1987) and feel that it helps them to dispel initial suspicion (Collins et al. 1988) and eliminate the surprise of an unexpected cold call (Dillman, Gallegos, and Frey 1976). Advance letters or prenotification e-mails are strongly advised for web surveys as well (Dillman 2000).

Advance letters underscore the legitimacy of a survey, take away suspicion, communicate the value of the survey, and evoke the principles of social exchange and reciprocation, thereby positively influencing response. Based on theoretical considerations (Dillman 1978; Goyder 1987; Groves and Couper 1998), advance letters should be an effective tool to increase response in telephone surveys as well, and their usage is suggested by telephone survey handbooks (e.g., Dillman 1978; Frey 1989; Lavrakas 1993; Fielder and Bouque 2002). However, an advance letter could also produce a negative effect in telephone surveys. It gives a clear forewarning of a survey and enables people to make their decision and prepare their response before they are contacted (Collins et al. 1988). This, in combination with the shorter time available and the fewer means and opportunities for interviewers in telephone surveys to persuade reluctant respondents (De Leeuw and Hox 2004), could make advance letters less successful in telephone surveys. These considerations have led to a number of empirical investigations into the effectiveness of advance letters specifically for telephone surveys. 
In this study, we integrate all available evidence and present a quantitative summary of empirical studies on the effectiveness of advance letters in raising the response in telephone surveys.

\section{Methods}

\section{ON META-ANALYSIS}

Meta-analysis or quantitative synthesis is a set of methods for the systematic combination of information from different sources. Meta-analysis provides a statistical summary of what is common, and analyzes what is different. It provides researchers with a quantifiable summary, which may be used to evaluate past research, and in addition, can help in identifying gaps in the knowledge found in the published literature (Selden 1992; Lipsey and Wilson 2001). Therefore, meta-analysis is both an effective tool to summarize what is known about the effectiveness of advance letters on response in telephone surveys and to suggest future research in this field.

In a meta-analysis, quantitative study outcomes from known research on a particular, well-defined question, here "the effectiveness of advance letters in telephone surveys," are statistically combined. In general, an effect size measure is coded for the dependent variable study-outcome. Furthermore, background variables such as year of publication and source of publication are routinely coded, just as age and sex are routinely asked in a survey. Also, several research design characteristics of each study are coded (e.g., sampling method, type of subjects). This coding process results in a data matrix in which the cases (or rows) are the research studies of interest for the meta-analysis. Statistical procedures can then be used. In other words, the basic idea is to apply statistical methods, with the published statistics from previous studies as the data (De Leeuw and Hox 2003).

\section{RETRIEVAL AND SELECTION OF STUDIES}

An attempt was made to identify and retrieve the entire population of empirical studies on the effectiveness of advance letters in telephone surveys, including both published and unpublished studies. The following sources were used to identify potentially eligible research reports.

First, we targeted specialized sources and systematically searched the online proceedings of the Survey Methods Section of the American Statistical Association (AMSTAT) 1978-2000 (including the proceedings of the American Association for Public Opinion Research (AAPOR) conferences) at www.amstat.org. As the most recent conference proceedings are not online, we also searched the published AMSTAT conference CD-ROMs of the years 2001-2004. In 
addition, we searched both Public Opinion Quarterly and the Journal of Official Statistics (JOS)-online, and our archives of the international workshop of household survey nonresponse. Finally, the bibliography on telephone survey methodology by Khursid, Anwer, and Sahai (1995) was investigated.

In the second step, we performed a systematic computer search using the international silver platter system of the library of Utrecht University. This included the bibliographical databases of ERIC (Educational Resources Information Center), JSTOR (Journal Storage Archive), PsychINFO, PUBMED (including MEDLINE and PreMedline), Sociological Abstracts, and SSCI (Social Sciences Citation Index).

Third, to acquire as many unpublished papers and reports as possible, we used the electronic survey methodology network. An appeal for help was sent to the list-servers of AAPOR, the World Association for Public Opinion Research (WAPOR), the Survey Research Methodology Section of the AMSTAT (SMRS), and the Research Committee on Logic and Methodology of the International Sociological Association (RC33-BMS). In addition, the data bases of EAGLE (European Association for Grey Literature Exploitation), SIGLE (System of Information for Grey Literature Europe), and the UK center for evidence-based policy and practice (ESRC) were searched for "gray literature." This term refers to papers, reports, technical notes, or other documents produced and published by governmental agencies, academic institutions, and other groups that are not distributed or indexed by commercial publishers. Finally, the bibliographies of retrieved studies were examined for related studies.

The following keywords were used, both singly and in combination: telephone survey, telephone interview(s), advance letter(s), prenotification(s), lead letter, response, response rate(s), contactability, refusal(s). The inclusion criterion was that the study should report the results of a (quasi-) experimental study on the effect of an advance letter on the response in a telephone survey.

The search located 28 publications. In one publication, the experimental treatment "advance letter" was completely confounded with another variable, making it impossible to estimate the effect of the advance letter (i.e., an incentive was sent together with all advance letters, making it impossible to separate the individual effect of advance letter and incentive). A second publication was concerned with monthly Touchtone Data Entry (TDE) reporting of employment and productivity of establishments, instead of a telephone survey. Both publications were excluded from the meta-analysis, resulting in 26 publications eligible for analysis.

One study was reported in two separate publications, and the results of these two publications were combined into one case for the meta-analysis. Some publications reported two independent studies in the same publication; these were coded as separate cases. The net result was that 29 independent studies on the influence of advance letters on the response in telephone surveys were available for coding. The majority (23) had only one experimental condition (i.e., tested the effect of one advance letter), but several studies investigated more 
than one experimental condition. Two studies investigated the effect of two different forms of advance letters, three studies used three different versions of advance letters in the experiment, and one study investigated four different types of advance letters. In sum, the 29 independent studies incorporated 40 experimental conditions with a combined sample size of approximately 64,155 respondents.

Of the 29 independent studies, 12 were published in scientific journals, 3 were book chapters, 7 were published in conference proceedings, 2 were unpublished papers, and 5 were "gray" literature. The oldest publication was published in 1976, the most recent one dated 2005. Twenty-one experiments were performed in the USA, four in Europe, and four in Australia. The majority of the studies (17) were done at universities, eight by government agencies (e.g., department of health), two by national statistical agencies (e.g., census bureau), and two had a market research origin. A variety of topics were covered with health issues the most prominent. For a complete bibliography of publications incorporated in this meta-analysis, see Appendix A.

Only nine of the studies include the text of the advance letters used. We contacted the original authors of the other studies, asking them for the original text of the advance letters. This resulted in the full texts for an additional 12 studies, bringing the total number of conditions for which the text of the prenotification is available to 29 .

\section{Coding and Analysis}

A detailed coding schedule was developed based on the schedule used by De Leeuw (De Leeuw and Van der Zouwen 1988; De Leeuw 1992) and the schedule used by Lensvelt-Mulders et al. (2005). Three categories of information were coded: (1) effect size information, (2) study descriptors, and (3) specific information on the advance letters used (see Appendix B). All eligible studies were coded by two independent coders using a detailed coding schedule. A third reviewer checked all codings for consistency. The independent codings only showed trivial differences, which were reconciled by discussing the original article and codings with the coders and the reviewer.

\section{CODING OF EFFECT SIZE INFORMATION}

The main outcome variable in the studies is the response rate. Response rates can be defined in different ways. In this meta-analysis, we used both the cooperation rate and the response rate. The cooperation rate is defined as the proportion interviewed of all eligible cases contacted. The response rate is defined as the proportion interviewed of all interviews plus the number of noninterviews (refusals, noncontact, others) plus all cases of unknown eligibility. These definitions correspond to the standard definitions COOP1 and RR 1 of the 
AAPOR (2006). ${ }^{1}$ The majority of the studies reported these outcomes, some presented tables of final response dispositions from which these response rates could be calculated.

Most studies reported the number of cases on which these rates were based or information from which these could be inferred; some studies reported only the overall sample size, in which case the assumption was made that all conditions in the experiment had the same sample size. In the end, it was possible to code the cooperation rate for 25 studies, and the response rate for 24 studies. Only 11 studies provided sufficient information to calculate the contact rate. Since the effect of an advance letter occurs only after contact has been made, the contact rate is not used in our analysis.

The outcome variables cooperation rate and response rate are proportions. For our meta-analysis, these must be encoded in an effect size variable that is approximately normally distributed with a known sampling variance (based on the sample size). The appropriate effect size for comparing proportions between an experimental group and a control group is the logged odds ratio (Lipsey and Wilson 2001, p. 53) defined as

$$
\mathrm{LOR}=\log \left(\frac{p_{\text {Eresp }} / p_{\text {Enonresp }}}{p_{\text {Cresp }} / p_{\text {Cnonresp }}}\right),
$$

with $\mathrm{E}$ denoting the experimental condition and $\mathrm{C}$ the control condition. The sampling variance for the logged odds ratio is (Lipsey and Wilson 2001, p. 54)

$$
S_{\text {LOR }}^{2}=\frac{1}{N_{\text {Eresp }}}+\frac{1}{N_{\text {Enonresp }}}+\frac{1}{N_{\text {Cresp }}}+\frac{1}{N_{\text {Cnonresp }}} .
$$

We present the results of our meta-analysis on the odds-ratio scale. For interpretation, some of the analysis outcomes are also back-transformed to standard response rates (proportions).

\section{CODING OF STUDY DESCRIPTORS}

To be able to examine the relationships between effect sizes and study characteristics, a range of study descriptors were coded (cf. Mann 2005b). These

1. AAPOR (2006) standard definitions:

COOP1 is the minimum cooperation rate: the number of completed interviews divided by the number of interviews (complete and partial) plus the number of noninterviews that involve the identification of and contact with an eligible respondent (refusal and break-off plus other). COOP1 $=$ $\mathrm{I} /(\mathrm{I}+\mathrm{P})+\mathrm{R}+\mathrm{O}$.

RR1 is the minimum response rate: the number of completed interviews divided by the number of interviews (complete plus partial) plus the number of noninterviews (refusals and break-off plus noncontacts plus others) plus all cases of unknown eligibility. RR1 $=\mathrm{I} /(\mathrm{I}+\mathrm{P})+(\mathrm{R}+\mathrm{NC})+$ $(\mathrm{UH}+\mathrm{UO})$. 
included sampling characteristics (e.g., type of population, sampling frame), method/design characteristics (e.g., experimental design, time between advance letter and telephone call, duration of interview, contact attempts, refusal conversion, and interviewer quality), and survey characteristics (e.g., topic saliency and sensitivity, type of data). Also included were background variables relating to the context of the research report (e.g., publication type (reviewed or not), year and country of publication).

\section{CODING OF ADVANCE LETTER DESCRIPTORS}

Sending any advance letter will decrease the amount of surprise from an unexpected call and provide legitimacy and as such be effective (Link 2004). But some letters appear to be more effective than others and researcher search for the most effective arguments to employ (e.g., Luppes 1995; Australian Bureau of Statistics 2002; Link 2004). To help identify the characteristics of the most effective prenotification letter, specific information on the nature of the advance letters was coded. Content characteristics were comprehensively coded; the descriptors used were based on advice for content letters as published by Dillman (1978), Luppes (1995), and White, Martin, Bennett, and Freeth (1998). Among the characteristics coded were if the research agency and a contact for information were mentioned, if the goal and usefulness of the study was mentioned, if sampling procedures were explained, if a confidentiality statement was given, and if an explicit thank you was offered. In addition, it was coded if, in the text of the content letter, arguments were used derived from social psychological theory on compliance (see Cialdini 1984; Groves, Cialdini, and Couper 1992), and on social exchange (see Dillman 1978, 2000). These compliance arguments included use of authority (e.g., requests from proper authority such as government), scarcity (e.g., emphasis on rare opportunity to get your voice heard), social validation (e.g., others similar to you also participate), altruism (you will really help), and reciprocation/social exchange (e.g., immaterial thank you or promise of results, explicit incentive).

\section{ANALYSIS}

The data set includes 29 independent studies with 40 experimental conditions. These data can be viewed as two-level data with conditions nested within studies. However, preliminary analyses using multilevel meta-analysis (Hox 2002; Raudenbush and Bryk 2002; Hox and De Leeuw 2003) showed that the sample size of about 1.4 conditions per study is too small to separate study-level and condition-level variance. As a consequence, the data were analyzed using standard meta-analysis procedures (Lipsey and Wilson 2001) with conditions as the unit of analysis (a reanalysis with studies as the unit of analysis produced 
the same results). Since all analyses showed large and significant variability between outcomes, the analyses reported below are based on random effects weighted multiple regression using maximum likelihood estimation or REML (Hox and De Leeuw 2003).

\section{Results}

\section{GENERAL CHARACTERISTICS OF STUDIES}

The search of the literature yielded 29 eligible empirical studies. Table 1 summarizes the characteristics of these studies. The majority of the advance letter experiments were implemented in surveys of the general population, using random sampling procedures. In most of the cases, the questions were about the respondent, and only in a small number of cases, questions were asked about others, such as household members. What is striking is the lack of information in some of the publications. In only 9 out of 29 studies, the text of the advance letter was included in the publication, which gives a missing data rate of 69 percent. In a special attempt, we were able to retrieve the texts of advance letters in an additional 12 studies, reducing the missing information to 28 percent. Some of these studies used more than one experimental condition; as a result, the number of available advance letters is 29 . In three studies, important background characteristics, such as target and topic of the survey, were not mentioned. One study could be clearly identified as an outlier, and was therefore removed. ${ }^{2}$

\section{MEAN EFFECT ADVANCE LETTER}

Sending an advance letter does have a positive effect on both response rate and cooperation rate. The odds ratio for cooperating is 1.62 larger in the advance letter condition than in the control condition $(p<0.001,95$ percent CI is $1.47-$ 1.78), and the odds ratio for the response rate is 1.37 larger in the experimental condition $(p<0.001,95$ percent CI is $1.28-1.46)$. The small $p$-values and the

2. This condition shows a large negative effect of the advance letter. It concerns a study of the French ASCF Group 1992, in which two types of advance letter were used: a standard advance letter and a modified advance letter. The paper is about a national survey of the French National Health Institute (INSERM) into health and sexual behavior. The standard advance letter just mentioned that it concerned a large health survey, and stressed the importance of the study, but also stated that one had the option not to answer and gave a strict anonymity assurance. The French ethical commission CNIL requested that the respondents were clearly informed that the survey was on sexual behavior and Aids. The modified advance letter stating this explicitly and at length had a large negative effect on the response rate, while the standard advance letter had the expected positive effect. Since an outlier can bias results, especially of multivariate analyses (Tabachnick, Barbara, and Fidell 2001), we decided to exclude this outlier from the analysis. Removal of this outlier, in fact, did not greatly change the results discussed below. 
Table I. General Characteristics of the 29 Studies Included in the MetaAnalysis

\begin{tabular}{|c|c|c|}
\hline & $N_{\text {tot }}{ }^{\mathrm{a}}$ (percent) & $N$ (percent) \\
\hline \multicolumn{3}{|l|}{ Sampling characteristics } \\
\hline Population & $29(100)$ & \\
\hline General & & $20(69)$ \\
\hline Special & & $9(31)$ \\
\hline Sampling frame & $29(100)$ & \\
\hline RDD & & $8(28)$ \\
\hline Telephone book & & $9(31)$ \\
\hline National lists & & $6(21)$ \\
\hline Lists from organizations & & $5(17)$ \\
\hline Panel & & $1(3)$ \\
\hline Sampling procedure & $29(100)$ & \\
\hline Random & & $29(100)$ \\
\hline Nonrandom & & $0(0)$ \\
\hline \multicolumn{3}{|l|}{ Survey and design characteristics } \\
\hline Assignment to conditions & $29(100)$ & \\
\hline Random & & $27(93)$ \\
\hline Nonrandom & & $2(7)$ \\
\hline Text letter in publication & $29(100)$ & \\
\hline Yes & & $9(31)$ \\
\hline No & & $20(69)$ \\
\hline Time between letter and interview & $12(100)$ & \\
\hline Less than 4 days & & $5(42)$ \\
\hline Between 5 and 7 days & & $3(25)$ \\
\hline More than a week & & $4(33)$ \\
\hline Maximum \# of contact attempts & $15(100)$ & \\
\hline Minimum & & 2 \\
\hline Maximum & & 24 \\
\hline Average \# of contact attempts needed & $4(100)$ & \\
\hline Minimum & & 2.5 \\
\hline Maximum & & 7.6 \\
\hline Refusal conversion used & $16(100)$ & \\
\hline Yes & & $7(44)$ \\
\hline No & & $9(56)$ \\
\hline Duration interview & $17(100)$ & \\
\hline Short $(<5$ minutes $)$ & & $2(12)$ \\
\hline Medium & & $14(82)$ \\
\hline Long (>30 minutes) & & $1(6)$ \\
\hline Interviewer quality & $24(100)$ & \\
\hline Experienced & & $17(71)$ \\
\hline Specially trained for occasion & & $7(29)$ \\
\hline Topic saliency & $26(100)$ & \\
\hline Nonsalient & & $2(8)$ \\
\hline
\end{tabular}


Table I. Continued

\begin{tabular}{lcc}
\hline & $N_{\text {tot }}{ }^{\mathrm{a}}$ (percent) & $N$ (percent) \\
\hline Neutral & & $8(31)$ \\
Salient & & $15(58)$ \\
Very salient & $26(100)$ & $1(4)$ \\
Topic sensitivity & & \\
Not sensitive & & $11(42)$ \\
Somewhat & $9(35)$ \\
Sensitive & $26(100)$ & $5(19)$ \\
Definitely very sensitive & & $1(4)$ \\
Target questionnaire & \\
Self & & $22(85)$ \\
Household/family & $4(15)$ \\
\hline
\end{tabular}

${ }^{\mathrm{a}} N_{\text {tot }}$ indicates the number of codable cases (i.e., information provided in publication).

confidence intervals (CI) indicate that both odds ratios are significantly larger than one. Thus, the results clearly indicate that sending an advance letter helps. This effect is larger for the cooperation rate than for the response rate. This makes excellent sense. The cooperation rate reflects the willingness of people to respond after being contacted, and is a pure measure of the success of the advance letter. The response rate is an overall practical index, reflecting both the success in contacting persons, which cannot be influenced by an advance letter, and the success in convincing persons, which can be influenced.

We will discuss design characteristics and a moderator analysis in a subsequent section. However, one design characteristic is very relevant for using advance letters in a telephone survey, and this is whether the survey employs a sample based on random digit dialing (RDD) or a list-based sample. In RDD sampling, addresses are not available and must be obtained using a matching procedure. Advance letters can only be sent to that part of the RDD sample for which an address can be obtained. The effectiveness of an advance letter is expected to be much lower in an RDD than in a list-based survey. When the data are summarized separately for RDD and list-based designs, we find that this is indeed the case. In RDD studies, the odds ratio for cooperating is 1.27 larger in the advance letter condition than in the control condition $(p<0.001$, 95 percent $\mathrm{CI}$ is $1.16-1.39$ ), and the odds ratio for the response rate is 1.23 larger in the experimental condition ( $p<0.001,95$ percent $\mathrm{CI}$ is $1.14-1.33)$. In list-based studies, the odds ratio for cooperating is 1.87 larger in the advance letter condition than in the control condition $(p<0.001,95$ percent CI is $1.65-$ 2.13 ), and the odds ratio for the response rate is 1.48 larger in the experimental condition ( $p<0.001,95$ percent $\mathrm{CI}$ is $1.35-1.63)$.

Table 2 presents the increase in cooperation and response rates for the total sample and for RDD and list surveys separately as proportions, which facilitates 
Table 2. Average Cooperation and Response Rates for RDD- and List-Based Samples

\begin{tabular}{lccccc}
\hline & \multicolumn{4}{c}{ Outcome } \\
\cline { 2 - 3 } \cline { 5 - 6 } Sample & No letter & Advance letter & & No letter & Advance letter \\
\cline { 2 - 3 } RDD sample & 0.58 & 0.63 & & 0.47 & 0.51 \\
LIST sample & 0.68 & 0.81 & & 0.62 & 0.71 \\
Total & 0.64 & 0.75 & & 0.58 & 0.66 \\
\hline
\end{tabular}

interpretation and comparison. The results clearly indicate that sending an advance letter helps in both RDD and list surveys, but that the effect is much larger in list-based surveys, where, in principle, all sample members can be reached by mail. We will come back to the issue if RDD and the problem of finding matching addresses in the discussion.

\section{VARIABILITY IN RESULTS}

The meta-analysis of the effect sizes showed that the results are not homogeneous, meaning that the observed variability of the effect size estimates is much larger than expected from sampling error alone. For the response rate, the chi-square of the homogeneity test is $69.6(d f=28, p=0.00)$, and for the cooperation rate, the chi-square is $168.8(d f=34, p=0.00)$.

Homogeneity means that all variance between conditions is only sampling variance. In our case, there are real and significant differences between the conditions. In fact, the amount of systematic (nonsampling) variance between conditions is estimated as 65.7 percent for response rate and 86.1 percent for cooperation rate. It is clear that, in addition to sampling, other sources contribute considerably to the variation in outcomes. As a consequence of the heterogeneity, a random effects model was adopted for all analyses.

The next step in meta-analysis is to examine, and possibly, to explain the observed variability. Accordingly, we investigated if study and design characteristics could explain heterogeneity. The results are discussed below.

\section{EFFECTIVENESS OF ADVANCE LETTERS AND STUDY DESCRIPTORS}

For each outcome (RR1 and COOP1), we carried out three separate series of regression analyses. One regression used the methodological variables, one used the study design variables, and one used the advance letter characteristics.

First, we investigated if heterogeneity could be explained by characteristics of the studies themselves. Two types of "study" variables are available to explain these differences: methodological characteristics of the experiments and design characteristics of the studies themselves. The former gives an indication of 
Table 3. Predicting Variability in Response and Cooperation Rates Using Design Characteristics

\begin{tabular}{lrrrr}
\hline & \multicolumn{4}{c}{ Predictor } \\
\cline { 2 - 5 } Outcome & Beta & $p$ & $R^{2}$ & $N$ of cases \\
\hline Cooperation rate (COOP1) & & & & \\
$\quad$ List sample (vs. RDD) & 0.54 & 0.00 & 0.29 & 35 \\
$\quad$ Refusal conversion used & -0.48 & 0.01 & 0.23 & 17 \\
$\quad$ Average \# contact attempts needed & -0.93 & 0.00 & 0.87 & 5 \\
Response rate (RR1) & & & & \\
$\quad$ List sample (vs. RDD) & 0.47 & 0.00 & 0.22 & 29 \\
$\quad$ Average \# contact attempts needed & -0.89 & 0.00 & 0.80 & 5 \\
\hline
\end{tabular}

NOTE.-The results are univariate regressions on a logged odds-ratio scale.

methodological rigor; the latter tells for which type of survey advance letters are most effective.

Only a small number of study characteristics turned out to have a significant effect on the results found. Since many coded characteristics were not codeable for all studies and conditions (cf. table 1), there is a considerable amount of incomplete information. A full multivariate analysis including all study characteristics is impossible, since the resulting data set would have far more variables than cases. Therefore, we first report the results in table 3 as univariate regressions for those characteristics that show a significant effect. Table 3 gives for each variable the following results: standardized (beta) regression coefficient, $p$-value of the test on the significance of the regression, $R^{2}$, and the number $N$ of available cases for that variable. The results given in table 3 are reported on the logged odds-ratio scale.

None of the methodological variables showed a significant effect on the effectiveness of the advance letter for either cooperation or response rates. This means that the methodological differences in the 29 studies have no effect on the results found.

In general, the proportion of explained variance is larger for the cooperation rate than for the response rate. This is reasonable, because the response rate is diminished by noncontacts, which are removed in calculation of the cooperation rate. Advance letters do not reduce noncontacts, they help convince potential respondents after contact has been made.

For the cooperation rate, studies that are characterized by a large number of contact attempts needed before a contact was made showed a smaller effect of advance letters. These studies are apparently targeting a difficult-to-reach population, and it is possible that in the experimental group, many advance letters, in fact, did not reach their intended addressees. However, this explanatory variable could only be coded in five experimental conditions out of a total of four studies. This small number of cases makes it impossible to include this 
variable together with other explanatory variables in one multivariate analysis. A multiple regression including the two remaining study characteristics (list vs. RDD and refusal conversion) resulted in both predictors failing significance. Inspection of the correlations showed that using refusal conversion correlated -0.89 with using lists. Apparently, investigators almost never use refusal conversion in combination with list-based samples, which makes it impossible to disentangle the effects of these two variables.

For the interpretation, it is important to realize that the results in table 3 are based on logged odds-ratios. Thus, the effects must be seen as interaction effects. For example, the significant effect of list-versus-RDD means that the effect of an advance letter is larger in list-based samples, but it does not mean that an advance letter is useless when RDD is used. The same goes for refusal conversion: the effect of an advance letter is larger when combined with refusal conversion, but this does not imply that when refusal conversion is not used, an advance letter does not work. We discussed this earlier in the context of list versus RDD-based samples; table 2 provides the response rates that underlie the regression analyses reported in table 3 .

It should be emphasized that no significant effects were found for population, topic, sponsor, or any of the other variables listed in table 1 but not included in table 3. In other words, there are no indications that advance letters work differently for different population or topics. This means that advance letters are a general tool that can be applied in many different types of surveys. Year of publication also could not explain the heterogeneity, indicating that the effect of advance letters is not different over time. There was also no difference between different types of publication (refereed vs. nonrefereed).

\section{CHARACTERISTICS OF MOST EFFECTIVE ADVANCE LETTERS}

Advance letters do work, but what makes an advance letter most successful? Three types of variables code for differences in content of advance letters were available: those referring to format, those referring to content characteristics, and those referring to compliance arguments (see also Coding of Advance Letter Descriptors). Only 9 out of 29 studies presented the text of the advance letters used in the original publication, but we were able to retrieve the texts of advance letters used in 12 more studies, which brings the number of studies for which the full text of the advance letters was available to 21 out of $29 .^{3}$ In addition, publications that did not include the full text of the advance letter usually provided a limited description of its contents. As a result, some letter characteristics could be coded from this description. Still, considerable amounts

3. We really appreciate the extra effort authors made to provide us with copies of the advance letters used. 
Table 4. Characteristics of 40 Advance Letters (29 Coded from Original Letter, 11 Coded from Information in Publication) ${ }^{\mathrm{a}}$

\begin{tabular}{|c|c|c|c|c|c|}
\hline & $N_{\text {tot }}$ & $N_{\text {letter }}$ & Percentage & $N_{\text {publ }}$ & Percentage \\
\hline \multicolumn{6}{|l|}{ Format letter } \\
\hline Letter type & 37 & 29 & 100 & 8 & 100 \\
\hline Postcard & & 1 & 3 & 1 & 13 \\
\hline $\begin{array}{l}\text { Short (max. one page with broad } \\
\text { margins) }\end{array}$ & & 9 & 31 & 3 & 38 \\
\hline Medium (extended, one full page) & & 18 & 62 & 4 & 50 \\
\hline Long (more than one page) & & 1 & 3 & 0 & \\
\hline Letter length (number of words body text) & 29 & 29 & 100 & & - \\
\hline Mean & & & 234.4 & & - \\
\hline Median & & & 231.0 & & - \\
\hline Standard deviation & & & 80.3 & & - \\
\hline Language letter & 40 & 29 & 100 & 11 & 100 \\
\hline Native speakers only & & 27 & 93 & 11 & 100 \\
\hline Translations/bilingual & & 2 & 7 & 0 & \\
\hline Form of address & 39 & 29 & 100 & 10 & 100 \\
\hline Individually personalized & & 14 & 48 & 7 & 70 \\
\hline Addressed to household & & 4 & 14 & 1 & 10 \\
\hline Not personalized at all & & 11 & 38 & 2 & 20 \\
\hline \multicolumn{6}{|l|}{ Content characteristics } \\
\hline Research agency mentioned & 40 & 29 & 100 & 11 & 100 \\
\hline Yes & & 29 & 100 & 11 & 100 \\
\hline No & & 0 & & 0 & \\
\hline Contact info for questions, etc. & 37 & 29 & 100 & 8 & 100 \\
\hline Yes & & 22 & 76 & 6 & 75 \\
\hline No & & 7 & 24 & 2 & 25 \\
\hline What survey is about & 28 & 29 & 100 & 8 & 100 \\
\hline Yes & & 27 & 93 & 7 & 88 \\
\hline No & & 2 & 7 & 1 & 13 \\
\hline Usefulness mentioned & 34 & 29 & 100 & 5 & 100 \\
\hline Yes & & 25 & 86 & 5 & 100 \\
\hline No & & 4 & 14 & 0 & \\
\hline Anonymity/confidentiality & 34 & 29 & 100 & 5 & 100 \\
\hline Yes & & 23 & 79 & 5 & 100 \\
\hline No & & 6 & 21 & 0 & \\
\hline How did we get your address/phone & 33 & 29 & 100 & 4 & 100 \\
\hline Yes & & 15 & 52 & 4 & 100 \\
\hline No & & 14 & 48 & 0 & \\
\hline Why you are sampled & 31 & 29 & 100 & 4 & 100 \\
\hline Yes & & 11 & 38 & 3 & 75 \\
\hline No & & 18 & 62 & 1 & 25 \\
\hline Duration mentioned & 33 & 29 & 100 & 4 & 100 \\
\hline Yes & & 23 & 79 & 0 & \\
\hline No & & 6 & 21 & 4 & 100 \\
\hline
\end{tabular}


Table 4. Continued

\begin{tabular}{|c|c|c|c|c|c|}
\hline & $N_{\text {tot }}$ & $N_{\text {letter }}$ & Percentage & $N_{\text {publ }}$ & Percentage \\
\hline Duration in minutes (if mentioned, & 22 & 22 & 100 & - & \\
\hline was between 10 and 20 minutes) & & & & - & \\
\hline Mean & & & 14.4 & - & \\
\hline Median & & & 15.0 & - & \\
\hline Standard deviation & & & 5.1 & - & \\
\hline Summary of results promised & 33 & 29 & 100 & 4 & 100 \\
\hline Yes & & 1 & 3 & 0 & \\
\hline No & & 28 & 97 & 4 & 100 \\
\hline Explicit "thank you" & 33 & 29 & 100 & 4 & 100 \\
\hline Yes & & 18 & 62 & 4 & 100 \\
\hline No & & 11 & 38 & 0 & \\
\hline \multicolumn{6}{|l|}{ Compliance arguments used } \\
\hline Reciprocity/social exchange & 33 & 29 & 100 & 4 & 100 \\
\hline Yes & & 5 & 17 & 0 & \\
\hline No & & 24 & 83 & 4 & 100 \\
\hline Authority & 34 & 29 & 100 & 5 & 100 \\
\hline Yes & & 26 & 90 & 4 & 80 \\
\hline No & & 3 & 10 & 1 & 20 \\
\hline Scarcity & 33 & 29 & 100 & 4 & 100 \\
\hline Yes & & 3 & 10 & 0 & \\
\hline No & & 26 & 90 & 4 & 100 \\
\hline Social validation & 33 & 29 & 100 & 4 & 100 \\
\hline Yes & & 1 & 3 & 0 & \\
\hline No & & 28 & 97 & 4 & 100 \\
\hline Altruism & 33 & 29 & 100 & 4 & 100 \\
\hline Yes & & 25 & 86 & 3 & 75 \\
\hline No & & 4 & 14 & 1 & 25 \\
\hline
\end{tabular}

${ }^{\text {a}}$ Forty experimental conditions were used in 29 studies. This means that 40 different advance letters were tested. Hence, the maximum $N_{\text {tot }}$ of the coded characteristics is 40 . A smaller number indicates that the information was completely missing in those publications. $N_{\text {letter }}$ refers to characteristics coded from the available full letter, $N_{\text {publ }}$ refers to those cases in which characteristics had to be coded from the information in the publication because no letter was available.

of missing data remain in some cases. Table 4 gives an overview of the final codes and their source (letter itself or description of letter in publication).

Inspecting table 4, we learn that most letters do not use well-known compliance principles from the nonresponse literature. Only one letter promises a summary of results and one-third (33 percent) of the letters does not even end with an explicit "thank you" (cf. Dillman 1978). However, most letters do evoke the authority principle (overall 88 percent) and appeal to altruism (overall 85 percent); see Groves, Cialdini, and Couper (1992) for a discussion of compliance principles. What is really surprising is that some letters (three) do 
Table 5. Predicting Variability in Response and Cooperation Rates Using Letter Characteristics

\begin{tabular}{lrrrr}
\hline & \multicolumn{4}{c}{ Predictor } \\
\cline { 2 - 5 } Outcome & Beta & $p$ & $R^{2}$ & $N$ of cases \\
\hline Cooperation rate (COOP1) & & & & \\
$\quad$ Language adaptation & -0.32 & 0.04 & 0.10 & 35 \\
$\quad$ Reciprocation & 0.41 & 0.01 & 0.17 & 31 \\
$\quad$ Explain why sampled & 0.34 & 0.04 & 0.11 & 31 \\
Response rate (RR1) & & & & 23 \\
$\quad$ Reciprocation & 0.50 & 0.00 & 0.25 & 23 \\
\hline
\end{tabular}

NOTE.-The results are univariate regressions on a logged odds-ratio scale.

not even mention the goal of the survey or its value. But the question remains: does the content of the letter really matter?

To answer this question, we analyzed response differences between conditions using known characteristics of the advance letters. Table 5 presents the results of regression analyses on both the response and cooperation rate.

Table 5 shows the importance of using a reciprocity argument in the advance letter for both cooperation and response rate. Reciprocity is founded on social exchange theory (Dillman 1978). Explaining sampling, that is why a person or household was sampled, only affected cooperation rate. The negative effect of language adaptation on cooperation rate appears peculiar, but language adaptation in our studies means that a very general letter is used that is English on one side and Spanish on the other side. We will come back to this in the discussion.

For cooperation rate, an additional analysis was carried out using all three letter characteristics (reciprocity, language adaptation, and explanation why sampled) in a multiple regression model. In this model, the regression coefficients are similar to the results in table 5, but explaining the sampling is no longer significant. The explained variance in the multivariate model is 0.26 . For the interpretation, it is important to realize that the results in table 5 are based on logged odds-ratios. Thus, the effects must be seen as interaction effects: advance letters work, but they work better when the norm of reciprocity is evoked.

\section{Discussion}

Our meta-analysis showed that sending an advance letter improves the cooperation rate in telephone surveys on average by about 11 percent and the response rate by about 8 percent. No significant interaction effects were found for population, topic, or sponsor. Advance letters appear to be a general tool that can be applied in many different types of surveys. Can we generalize this conclusion to 
telephone surveys in general? A relevant issue in meta-analysis is the so-called file drawer problem, which refers to the possibility that studies are more easily published if they are significant. In other words, the studies included in the meta-analysis could be a biased sample of the population of studies, because studies that produce nonsignificant results do not get published but linger in their investigators' file drawer. The file drawer problem can be addressed in several ways. One approach is to calculate the fail-safe $N$, which is an estimate of how many studies reporting null results must be hidden away in file drawers to render the combined results of the studies that were located insignificant at the 5 percent level. In our case, our significant effect of an advance letter on the cooperation rate can be swept away provided we find 4,822 hidden studies all reporting no effect. The effect of an advance letter on the response rate disappears if we find 2,132 hidden studies reporting no effect. This is highly implausible, so the file drawer problem is unlikely to bias our results. The file drawer problem can also be examined using funnel plots and by calculating the correlation between the absolute effect size and the sample size (Lipsey and Wilson 2001). The funnel plot did not indicate publication bias, and the correlations between the effect size and the sample size were low and insignificant. It appears that the validity of our meta-analysis is not endangered by publication bias. However, it should be noted that the studies in our meta-analysis mainly concern university-based or governmental research, and it is unclear how well our results generalize to commercial and market research.

Another limitation of our meta-analysis is that one of the inclusion criteria was that there must be an explicit comparison with a control group. This increases the internal validity of our research, especially given our finding that none of the methodological variables had an effect. Thus, studies using random assignment found basically the same results as studies using a different assignment method. However, the result is that relatively only a small number of studies is available for our meta-analysis, which may weaken the generalizability of our results.

Our main finding is that advance letters clearly have a positive effect on response in telephone surveys, both with RDD- and list-based samples. When the sample is based on a list with known addresses, the effect is larger. There is considerable variation in the effectiveness of the advance letter, as indicated by the heterogeneity of the outcomes. One possible reason is variation in the content and style of the advance letters. The publications themselves provide, in most cases, very little information about the letter sent, so initially we could not analyze this factor. But after contacting the individual authors, we were able to get the text of advance letters for 21 of the 29 studies investigated, which corresponds to 29 full texts on a total of 40 experimental conditions (letters).

We found no evidence that the length of the advance letter influences the response rate. This could mean that a postcard is just as effective as a complete letter. This may have advantages, not only because a postcard costs less to 
produce and send, but also because a letter from an unknown sender may be viewed with some suspicion, especially at times when anthrax or otherwise contaminated letters are being mailed (cf. Hembroff et al. 2005). Still there were only two studies that explicitly compared postcards; advance postcards proved to be effective compared to not sending anything (Iredell et al. 2004), but advance postcards were less effective than advance letters with respect to response rates and less cost-effective as well (Hembroff et al. 2005). More research into postcards as a form of advance letters seems to be indicated.

Some letter characteristics hardly vary across the studies, reflecting the best practice recommendations from the literature (e.g., Dillman 2000; Australian Bureau of Statistics 2002; Link and Mokdad 2005). For instance, all letters mention the research agency, and authority is almost universally used, if only by sending the letter on official letterhead paper. On the other hand, very few letters promised a summary. So if we fail to find an effect for authority or the sending of a summary, this does not necessarily mean that it does not work, it is more likely to be the result of restriction of range (almost no variance) in this predictor. Other letter characteristics have more variance, but still do not show up in statistical analysis as effective, e.g., the altruism argument ( 28 used it, 5 did not). In such cases, it is more likely that this characteristic indeed does not have an effect.

What did work was using a reciprocity argument in the advance letter. Reciprocity means that in the advance letter, the researcher is not only asking information from the respondent, but also offering information, e.g., by providing explanations about study and the sampling process or promising a summary report. This is consistent with social exchange theory (Dillman 1978, 2000) and with the positive effect reported in the literature for using incentives (Singer et al. 1999; Singer 2002). The negative effect of using language-adapted letters is interpreted as indicating a clear absence of tailoring (cf. Groves and Couper 1998). The studies that used language adaptation in their advance letters did send out a very general letter, English on one side and Spanish on the other side. In our view, the implicit message such a letter conveys is the opposite of personalization and tailoring: "we do not know who you are; we even do not know which language you speak." This does not mean that language adaptation cannot and should not be used in advance letters. Especially in surveys of special populations, or follow-up studies, tailored language adaptations may be effective. If a tailored approach is not possible, we suggest drawing upon well-established principles, such as social exchange, to counteract the impersonal image of a multiple language letter. For instance, by explaining how important it is for this special study to have respondents from different cultural backgrounds and emphasizing that this is the reason why the researchers have prepared special language adapted versions of the letter. Availability of a toll-free number and multilingual staff for questions will further invoke the reciprocity norm and should, if possible, be emphasized in the letter too. 
A different reason for the variation in the effect of advance letters could be an interaction with the text and style of the introduction at the start of the telephone call. An unexpected telephone call from stranger can give such a strong negative reaction that respondents are oblivious to even substantial variation in the introduction of the call (Dillman, Gallegos, and Frey 1976). An advance letter not only eliminates the elements of surprise, it also provides tangible evidence that the interview is legitimate and the telephone call is neither a sales gimmick, nor a practical joke (Dillman 1978, p. 243). As a result, the recipient is likely to be more receptive and listens better to what is being said.

As a final discussion point, finding an effect of an advance letter assumes that the advance letter has indeed been received and noticed. The first problem here is obtaining the addresses if RDD or a similar method is used. It is not always possible to match an address to a telephone number. The matching rate of addresses and telephone numbers will also vary from country to country. In the USA, from a practical point of view, matching addresses to phone numbers in a RDD survey is becoming more and more difficult. The matching rate varies from state to state and is lower in urban areas (Traugott, Groves, and Lepkowski 1987; Camburn et al. 1995; Brick and Collins 1997; Parsons, Owens, and Skogan 2002; Link 2004). At present, the average matching rate for an equal probability RDD is around 40 percent. This data is for mailable addresses that can be send a prenotification. Not all listed numbers have a mailable address. Some people choose to list their phone number but not their complete address, for example, omitting street and apartment number. Others list where they live but not where they receive their mail (Survey Sampling International, personal communication, January 19, 2006).

In addition, the intended respondent may not receive or may fail to notice the advance letter. Iredell et al. (2004) report how many contacted respondents recall being sent a postcard. In their total sample of 155 respondents who were sent a postcard, 107 (69 percent) remembered receiving it. In this group, 86 percent agreed to participate in the survey, as compared to 56 percent of the respondents who were sent a postcard but did not remember receiving it. In the comparison group who were not sent a postcard, the response rate was 59 percent (Iredell et al. 2004: table 5). In several advance letter experiments, respondents were explicitly asked if they recall the letter. Link and Mokdad (2005) report that 61 percent remembered seeing the prenotification letter, but this percentage varied between subgroups, with a higher percentage for the higher educated and white non-Hispanic subgroups. Parsons, Owen, and Skogan (2002) report that 50-58 percent of the respondents that were mailed a letter remembered receiving it with the lower percentage in the city of Chicago and the higher in the state of Illinois. Groves and Snowden (1987) report that in the general population (NHIS), about 75 percent of the respondents recall receiving the advance letter. In an evaluation study by Snow, Prather, and Hutchinson (1986), an exceptional high proportion (90 percent) remembered 
having received a letter. This high percentage may be caused by the special nature of the study: the respondents were all part of a very intensive training program and were very involved. In sum, a sizeable group of respondents does not remember receiving an advance notification. Why people remember advance letters is a topic for future research, as it would appear important to maximize the visibility of the advance letter or postcard. This is also important for the balance of costs versus benefits. Those studies that investigate the cost factor report that advance letters appear cost effective, although this obviously depends strongly on the cost structure of the organization sending out the survey (Singer, Hoewyk, and Maher 2000; Hembroff et al. 2005).

Finally, increasing the response rate to a survey, telephone or otherwise, is never the result of varying just one factor in the design. Advance letters appear to work well, but other factors such as using incentives are also known to be important (Singer et al. 1999; Singer 2002; Cantor, O'Hare, and O'Connor 2006). It is also possible that such factors interact, for instance, when an advance letter is used to provide a monetary incentive (Singer, Hoewyk, and Maher 2000). Good survey design should aim to combine all factors that are known to stimulate response rates in a comprehensive system (Dillman 2000). In addition, further research into the effect of advance letters in telephone surveys should aim to include such possible interactions in the design and make them an explicit object of study. It should be noted that a higher response rate can potentially reduce nonresponse error, but a high response rate is not enough. Nonresponse error has two components: the nonresponse error for a particular statistic is the product of the nonresponse rate and the difference between respondents and nonrespondents (e.g., Groves and Couper 1998; Couper and De Leeuw 2003). However, auxiliary information on both respondents and nonrespondents is rarely available as is reflected in our meta-analysis where almost all studies focused on reducing the nonresponse rate. Although difficult, it is not impossible to collect information for both respondents and nonrespondents in nonresponse studies (Groves and Couper 1998), especially for special populations (e.g., Goldstein and Jennings 2002; Mann 2005a). We therefore strongly advise to focus on nonresponse error in future response inducing studies.

\section{Acknowledgement}

We thank the extremely helpful members of the discussion lists of AAPOR, SRMS, WAPOR, and RC33 for their help in searching for references, and the virtual community of the international workshop on household nonresponse for their comments and suggestions. Many colleagues from all over the world sent us references and reports and enabled us to perform this meta-analysis. Special thanks to all who searched their old files and provided us with copies of their original advance letters, some going as far back as the early seventies. Without this help of many, the manuscript could never have been written. 
We also thank Linda Piekarski for the information on the current U.S. phone numbers-addresses matching rates.

\section{Appendix A}

\section{BIBLIOGRAPHY OF STUDIES INCORPORATED IN THE META-ANALYSIS}

Brehm, John. 1994. "Stubbing Our Toes for a Foot in the Door? Prior Contact, Incentives and Survey Response." International Journal of Public Opinion Research 6(1):45-63.

Brick, Michael J., and Mary A. Collins. 1997. "A Response Rate Experiment for RDD Surveys." In Proceedings of the 52nd annual conference of the American Association for Public Opinion Research, pp. 1052-58. Alexandria, VA: American Statistical Association.

Camburn, Donald, Paul J. Lavrakas, Michael P. Battaglia, James T. Massey, and Robert A. Wright. 1995. "Using Advance Respondent Letters in RandomDigit-Dialing Telephone Surveys." In Proceedings of the 50th annual conference of the American Association for Public Opinion Research, pp. 969-74. Alexandria, VA: American Statistical Association.

Collins, Martin, Wendy Sykes, Paul Wilson, and Norah Blackshaw. 1988. "Nonresponse: The UK Experience." In Telephone Survey Methodology, eds. Robert M. Groves, Paul P. Biemer, Lars E. Lyberg, James T. Massey, William L. Nicholls, II, and Joseph Waksberg, pp. 213-31. New York: Wiley. (Note: two advance letter studies reported).

Dillman, Don, Jean Gordon Gallegos, and James H. Frey. 1976. "Reducing Refusal Rates for Telephone Interviews.” Public Opinion Quarterly 40(1):6678.

Eyerman, Joe, Michael W. Link, Ali Mokdad, and Jeremy Morton. 2003. “Assessing the Impact of Methodological Enhancements on Different Subpopulations in an Experiment on the Behavioral Risk Factor Surveillance System." In Proceedings of the Section on Survey Research Methods of the American Statistical Association, pp. 1357-61. Alexandra, VA: American Statistical Association. (Note this is same experiment as reported by Link et al. 2003. The results reported in these two publications are combined and treated as one study in the meta-analysis).

Gerritsen, Marinel, and Marie-José Palmen. 2002. "The Effect of Prenotification Techniques on Refusal Rate in Telephone Surveys. A Real-Life Study in the Light of the Compliance and Elaboration Likelihood Theories." Document Design 3(1):16-28.

Goldstein, Kenneth M., and Kent M. Jennings. 2002. "The Effect of Advance Letters on Cooperation in a List Sample Telephone Survey." Public Opinion Quarterly 66(4):608-17. 
Groupe d'analyse des comportements sexuels en France (ASCF-Group). 1992. "Analysis of Sexual Behavior in France (ASCF): What Kind of Advance Letter Increases the Acceptance Rate in a Telephone Survey Behavior." Bulletin de Methodologies Sociologique 35(June):46-54.

Groves, Robert M., and Cecilia Snowden. 1987. "The Effects of Advance Letters on Response Rates in Linked Telephone Surveys." In Proceedings of the Section on Survey Research Methods of the American Statistical Association, pp. 633-38. Alexandria, VA: American Statistical Association.

Haggard, Lois M., and Donald Z. Gray. 1994. "Improving Validity of Parental Report of Child Immunizatin Status in a Telephone Survey." In Proceedings of the Section on Survey Research Methods of the American Statistical Association, pp. 1258-62. Alexandria, VA: American Statistical Association.

Hembroff, Larry A., Debra Rusz, Ann Rafferty, Harry Mcgee, and Nathaniel Ehrlich. 2005. "The Cost-Effectiveness of Alternative Advance Mailings in a Telephone Survey." Public Opinion Quarterly 69(2):232-45.

Iredell, H., T. Shaw, P. Howatt, R. James, and J. Granich. 2004. "Introductory Postcards: Do They Increase Response Rate in a Telephone Survey of Older Persons?" Health Education Research 19(2):159-64.

Kennedy, John M., Roger B. Parks, Nancy Bannister, Jennifer Inghram, and Heather Terhune. 1998. "An Analysis of the Effect of Varying Presurvey Letter Characteristics on Cooperation Rates." Available at http://www.indiana.edu/ csr/IUCSR_AAPOR98.pdf (accessed September 2005).

Link, Michael W., and Ali Mokdad, 2005. "Advance Letters as a Means of Improving Respondent Cooperation in Random Digit Dial Studies: A Multistate Experiment." Public Opinion Quarterly 69:572-87. (Note this covers the same experiment as reported in Link et al. 2003, and in Eyerman et al. 2003. The results reported in these three publications are combined and treated as one study in the meta-analysis).

Link, Michael W., Ali Mokdad, Machelle Town, Jodie Weiner, and David Roea. 2003. "Improving Response Rates for the BRFSS: Use of Lead Letters and Answering Machine Messages." In Proceedings of the annual conference of the American Association for Public Opinion Research, pp. 141-48. Alexandra, VA: American Statistical Association.

Mann, Christopher B. 2003. "Getting Pre-Election Surveys Right: The Effects of Advance Letters on Pre-Election Forecasting." Available at http://bbs.vcsnet.com/pdf/Mann-AAPOR_2003.pdf (accessed September 2005). (Note two studies: Maryland study differed from New York/ Pennsylvania study).

Mann, Christopher B. 2005. "Do Advance Letters Improve Preelection Forecast Results?" Public Opinion Quarterly 69:561-71. (Note: This is the same experiment as reported by Mann 2003; the results are combined and analyzed as one publication). 
Mickey, Ruth M., Pamela M. Vacek, and John K. Worden. 1999. "Effects of Survey Mode and Advance Letters on Contact and Interview Completion Rates for Population-Based Surveys of Women." In Proceedings of the Section on Survey Research Methods of the American Statistical Association, pp. 854-58. Alexandria, VA: American Statistical Association.

Parks, Roger B., John M. Kennedy, and Laura Frye Hecht. 1994. "A Demographic Analysis of the Impact of Presurvey Letters on Cooperation Rates in Urban Neighborhoods." Paper presented at the annual meeting of the American Association for Public Opinion Research, Danvers, MA, May 1994. Available at http://www.Indiana.edu/ csr/polpaper.html (accessed September 2005). (Note only study 2 was used).

Parsons, Jennifer, Linda Owens, and Wes Skogan. 2002. "Using Advance Letters in RDD Surveys: Results of Two Experiments." Survey Research Newsletter 33(1):1-2. (Note: Two advance letter studies reported).

Robertson, Brent, Martha Sinclair, and Andrew Forbes. 2000. "The Effect of an Introductory Letter on Participation Rates Using Telephone Recruitment." Australian and New Zealand Journal of Public Health 24:5.

Singer, Eleanor, John Van Hoewyk, and Mary P. Maher. 2000. "Experiments with Incentives in Telephone Surveys.” Public Opinion Quarterly 64(2):17188.

Smith, Wayne, Tien Chey, Bin Jaludin, Glenn Salkeld, and Tony Capon. 1995. "Increasing response rates in telephone surveys: A randomized trial" Journal of Public Health Medicine 17(1):33-8.

Snow, Robert E., James E. Pratcher, and John D. Hutcheson, Jr. 1986. "Program Evaluation Using a Follow-Up Telephone Survey. The Effects of a Prior Letter." Evaluation Review 10(1):85-94.

Traugott, Michael W., and Kenneth Goldstein. 1993. "Evaluating Dual Frame Samples and Advance Letters as a Means of Increasing Response Rates." In Proceedings of the 48th annual conference of the American Statistical Association, pp. 1284-6. Alexandria, VA: American Statistical Association. (Note: Two advance letter studies reported).

Traugott, Michael W., Robert M. Groves, and James M. Lepkowski. 1987. "Using Dual Frame Designs to Reduce Nonresponse in Telephone Surveys." Public Opinion Quarterly 51(4):522-39.

White, Bob, and Ian Ford. 2001. "Draft Methodology Report for the Australian Sports Commission." Exercise, Recreation and Sport Survey and Active Australia Awareness Survey. Australia: AC Nielsen.

\section{Appendix B}

\section{CODING SCHEDULES USED IN THE META-ANALYSIS}

Note: Coders also had access to the AAPOR response rate definitions, to excerpts from the book by Groves and Couper 1998 on nonresponse in household 
surveys and annotated examples of letters from the books by Dillman 1987 and Dillman 2000 on mail, telephone, and Internet surveys.

Coding Schedule Used to Code General Study Information + Control Condition

Note: if no information whatsoever about a coded characteristic: missing (leave blank). If information available but characteristic is absent: Code No

\section{General Research Characteristics}

Coder

1.2. 3 .

Full bibliographical info APA style

Publication:

(Authors, year, title, publication, pages). Only on this code schedule, not in SPSS-file.

Study identification (not for coder, but centrally)

Publication form

Publication type

Publication year

Country in which study was done

Origin (sponsor)

Number of study $(1,2,3, \ldots$, etc. $)$

1: Book

2: Journal article

3: Book chapter

4: Thesis or doctoral

5: Unpublished conference paper or technical report

6: Published paper or technical report (e.g., in conference proceedings)

7: Gray literature / Internet

8: Others

1: Not reviewed

2: Reviewed

In numbers

1: USA

2: Europe

3. Canada

4. Australia

5: Other

1: Official statistics (census, bls, etc)

2: Government (department health, etc)

3: University

4: Market research

5: Other, that is ...

\section{Sampling Characteristics}

Population

1: General population

2: Special population (restricted group, e.g., elderly) 
Sampling frame

Sampling procedure

\section{Design/Research Procedures}

Assignment to experimental conditions (letters)
More than 1 experimental condition?
That is are there other experimental conditions studied in same experiment (e.g., incentives)

Is the extra condition used in a factorial design?

Methodological details in publication

Quality of study (based a.o. on sampling procedure, assignment to conditions, methodological details)

Maximum number of contact attempts (by phone, that is how often should one try before it is allowed to classify it as unreachable/no answer)

Average number of contact attempts needed

Refusal conversion used

Time between letter and first tel. call Text advance letter(s) in publication

\section{Duration interview in minutes}

Duration interview

Interviewer quality (e.g., mention of large experience or special training, may mark more than one)
1: RDD (random digit dialing)

2: (Inter)national lists

3: List from organization, for instance, university or commercial organizations

4: Telephone book

5. Panel

6: Others

1: Random

2: Nonrandom

1: Random

2: Nonrandom

1: Yes

2: No

1: Yes

2: No

1: None

2: Some

3: Detailed (almost) complete

1: Poor

2: Fair

3: Good

1: Yes

2: No

In days:

1: Yes

2: No

\section{In minutes:}

1: Short ( $<5$ minutes)

2: Medium

3: Long (>30 minutes)

0 : Not mentioned

1: Experienced

2: Specially trained for the occasion 
Survey/Questionnaire Characteristics

Topic (may circle more than one)

Topic salience

Topic sensitivity

(see enclosed list for examples)

Target of questionnaire

(May circle more than one)

Type of data requested
1: Consumer

2: Finances, budget

3: Health

4: Media research

5: Education

6: Travel

7: Voting/election

8: Living conditions

9: Crime/victimization

10: General (social) attitudes

11: Omnibus

1: Nonsalient (repulsive/very boring)

2: Neutral

3: Salient

4: Very salient

0 : Not sensitive at all

1: Somewhat sensitive

2: Sensitive

3: Definitely very sensitive

1: Self

2: Household/family

3: Work organization/ establishment

4: Other, that is ...

1: Factual

2: Behaviour

3: Attitudinal/evaluation/ satisfaction

4: Mixed

Outcome control condition (coded separately by statistician based on marked parts in articles/papers) AAPOR Definitions used

Contact rate

$N$. of contact rate

Cooperation rate

$N$. of coop rate

Response rate

$N$. of response rate

Unmatch1

Unmatch2

0 if case removed, 1 if transferred to control (no letter) group, 9 if not applicable, leave blank if uncodeable

Proportion unmatchable cases 


\section{Coding Schedule for Experimental Condition}

Note: if no information whatsoever about a coded characteristic: missing (leave blank). If information available but characteristic is absent: Code No

\section{General Research Characteristics}

Coder

Full bibliographical info APA style (authors, year, title, publication, pages). Only on this code schedule, not in file

Study identification. (Write also on master copy done centrally, not by coder) Coder, please do: if more than one experimental condition identify by $a, b, c$

\section{Characteristics letter}

Letter type

\section{Length letter in number of words (count in lett
in appendix). Note: count text only, so not letterhead \& signature \\ Language letter}

Way letter is addressed

Content letter: research agency mentioned letterhead
or in letter
Content letter: contact for more information
mentioned (phone, or web, or address)
Content letter: goal mentioned what is survey about

1. 2. 3.

Publication:

Number of study: experimental condition (a,b,c, etc):
0: Postcard

1: Short /basic (less than one page, one page with a lot of white space, broad margins)

2: Medium: extended (a full page, small margins)

3: Long (more than one page)

Number words:

1: Only native speakers

2: Language adaptations/ translations

1: Really personalized (personal individual name mentioned)

2: Household (address mentioned in letter)

3. Not personalized at all

1: Yes

2: No

1: Yes

2: No

1: Yes

2: No

1: Yes

2: No

1: Yes

2: No 
Content letter: explanation source address (how did we get your address/phone \#)

Content letter: mentions reason why you (or household) is sampled (explanation sample)

Content letter: explanation further sampling procedure on phone (e.g., oldest female, next birthday, kish method, etc.)

Content letter: duration mentioned

Incentive

Content letter: incentive mentioned

Content letter: summary of results promised

Content letter: explicit thank you (e.g., at end)

Content letter: principle of reciprocation/social exchange used (tit-for-tat, obligation, material as an incentive or immaterial thank you)

Content letter: principle of authority is used (request clearly comes from authority, e.g., federal agencies, research firms with legitimacy, signed by VIP)

Content letter: scarcity principle is used (e.g., emphasis on rare opportunity to get your voice heard

Content letter: principle of validation is used (others like you also ....)

Content letter: altruism (you will help us, help ...)

Letter available in report/article
1: Yes

2: No

1: Yes

2: No

1: Yes

2: No

1: Yes, ..., minutes

2: No

0 : No incentive used

1: Incentive enclosed

2: Incentive promised

1: Yes

2: No

1: Yes

2: No

1: Yes

2: No

1: Yes

2: No

1: Yes

2: No

1: Yes

2: No

1: Yes

2: No

1: Yes

2: No

1: Yes

2: No

Outcome experimental condition (coded separately based on marked parts by statistician) AAPOR definitions used

Contact rate

$N$. of contact rate

Cooperation rate

$N$. of cooperation rate

Response rate

$N$. of response rate

\section{References}

American Association for Public Opinion Research. 2006. Standard Definitions: Final Dispositions of Case Codes and Outcome Rates for Surveys, 4th ed. Lenexa KS: AAPOR 
Australian Bureau of Statistics. 2002. "Advance Letters. An ABS Approach." Available at http://www.sch.abs.gov.au/SCH/A1610103.NSF/ResearchPapers (accessed January 2006).

Brick, Michael J., and Mary A. Collins. 1997. "A Response Rate Experiment for RDD Surveys." In Proceedings of the 52nd Annual Conference of the American Association for Public Opinion Research, pp. 1052-58. Alexandria, VA: American Statistical Association.

Camburn, Donald, Paul J. Lavrakas, Michael P. Battaglia, James T. Massey, and Robert A. Wright. 1995. "Using Advance Respondent Letters in Random-Digit-Dialing Telephone Surveys." In Proceedings of the 50th Annual Conference of the American Association for Public Opinion Research, pp. 969-74. Alexandria, VA: American Statistical Association.

Cantor, David, Barbara C. O'Hare, and Kathleen S. O'Connor. 2006. "The Use of Monetary Incentives to Reduce Nonresponse in Random Digit Telephone Surveys." Paper presented at the second international conference on telephone survey methodology (TSM II), January 11-15, Miami, FL.

Cialdini, Robert B. 1984. Influence: The New Psychology of Modern Persuasion. New York: Quill.

Collins, Martin, Wendy Sykes, Paul Wilson, and Norah Blackshaw. 1988. "Nonresponse: The UK Experience." In Telephone Survey Methodology, eds. Robert M. Groves, Paul P. Biemer, Lars E. Lyberg, James T. Massey, William L. Nicholls, II, and Joseph Waksberg, pp. 213-31. New York: Wiley.

Couper, Mick P., and Edith D. De Leeuw. 2003. "Nonresponse in Cross-Cultural and CrossNational Surveys." In Cross-Cultural Survey Methods, eds. Janet Harkness, Fons J. R. Van de Vijver, and Peter Ph. Mohler, pp. 157-77. Hoboken, NJ: Wiley.

De Leeuw, Edith D. 1992. Data Quality in Mail, Telephone, and Face-to-Face Surveys. Amsterdam: TT-Publikaties.

De Leeuw, Edith D., and Wim de Heer. 2002. "Trends in Household Survey Nonresponse: A Longitudinal and International Comparison." In Survey Nonresponse, eds. Robert M. Groves, Don Dillman, John L. Eltinge, and Roderick J. A. Little, pp. 41-54. New York: Wiley.

De Leeuw, Edith D., and Joop J. Hox. 2003. "The Use of Meta-Analysis in Cross National Studies." In Cross-Cultural Survey Methods, eds. Janet Harkness, Fons J. R. van de Vijver, and Peter Ph. Mohler, pp. 329-45. New York: Wiley.

De Leeuw, Edith D., and Joop J. Hox. 2004. "I Am Not Selling Anything. 29 Experiments in Telephone Introductions." International Journal of Public Opinion Research 16(4):464-73.

De Leeuw, Edith D., and Johannes Van der Zouwen. 1988. "Data Quality in Telephone and Face to Face Surveys: A Comparative Meta Analysis." In Telephone Survey Methodology, eds. Robert M. Groves, Paul P. Biemer, Lars E. Lyberg, James T. Massey, William L. Nicholls II, and Joseph Waksberg, pp. 283-99. New York: Wiley.

Dijkstra, Wil, and Johannes H. Smith. 2002. "Persuading Reluctant Recipients in Telephone Surveys." In Survey Nonresponse, eds. Robert M. Groves, Don Dillman, John L. Eltinge, and Roderick J. A. Little, pp. 121-34. New York: Wiley.

Dillman, Don A. 1978. Mail and Telephone Surveys. The Total Design Method. New York: Wiley.

Dillman, Don A. 2000. Mail and Internet Surveys. The Tailored Design Method. 2nd ed. New York: Wiley.

Dillman, Don A. 2002. "Navigating the Rapids of Change: Some Observations on Survey Methodology in the Early 21st Century." Public Opinion Quarterly 66(3):473-94.

Dillman, Don, Jean Gordon Gallegos, and James H. Frey. 1976. "Reducing Refusal Rates for Telephone Interviews." Public Opinion Quarterly 40(1):66-78.

Fielder, Eve P., and Linda B. Bouque. 2002. How to Conduct Telephone Surveys. 2nd ed. Newbury Park: Sage.

Frey, James H. 1989. Survey Research by Telephone. 2nd ed. Newbury Park, CA: Sage.

Goldstein, Kenneth M., and Kent M. Jennings. 2002. "The Effect of Advance Letters on Cooperation in a List Sample Telephone Survey." Public Opinion Quarterly 66(4):608-17.

Goyder, John. 1987. The Silent Minority: Nonrespondents on Sample Surveys. Cambridge: Polity Press. 
Groupe d'analyse des comportements sexuels en France (ASCF-Group). 1992. "Analysis of Sexual Behavior in France (ASCF): What Kind of Advance Letter Increases the Acceptance Rate in a Telephone Survey Behavior." Bulletin de Methodologies Sociologique 35(June):4654.

Groves, Robert M., Robert B. Cialdini, and Mick P. Couper. 1992. "Understanding the Decision to Participate in a Survey." Public Opinion Quarterly 56(4):475-95.

Groves, Robert M., and Mick P. Couper. 1998. Nonresponse in Household Interview Surveys. New York: Wiley.

Groves, Robert M., and Katherine A. McGonagle. 2001. "A Theory-Guided Interviewer Training Protocol Regarding Survey Participation.” Journal of Official Statistics 17(2):249-65.

Groves, Robert M., Barbara C. O’Hare, Dottye Gould-Smith, Andy McCann, Sue Ellen Hansen, José Benkí, and Patty Maher. 2006. "Telephone Interviewer Voice Characteristics and the Survey Participation Decision." Paper presented at the second international conference on telephone survey methodology (TSM II), January 11-15, Miami, FL.

Groves, Robert M., and Cecilia Snowden. 1987. "The Effects of Advance Letters on Response Rates in Linked Telephone Surveys." In Proceedings of the Section on Survey Research Methods of the American Statistical Association, pp. 633-38. Alexandria, VA: American Statistical Association.

Heberlein, Thomas A., and Robert B. Baumgartner. 1978. "Factors Affecting Response Rates to Mailed Questionnaires: A Quantitative Analysis of the Published Literature." American Sociological Review 43(4):447-62.

Heberlein, Thomas A., and Robert B. Baumgartner. 1981. "The Effectiveness of the HeberleinBaumgartner Models for Predicting Response Rates to Mailed Questionnaires: European and US Examples.” American Sociological Review 46(3):363-67.

Hembroff, Larry A., Debra Rusz, Ann Rafferty, Harry Mcgee, and Nathaniel Ehrlich. 2005. "The Cost-Effectiveness of Alternative Advance Mailings in a Telephone Survey." Public Opinion Quarterly 69(2):232-45.

Hox, Joop J. 2002. Multilevel Analysis. Techniques and Applications. Mahwah, NJ: Lawrence Erlbaum.

Hox, Joop J., and Edith D. De Leeuw. 2003. "Multilevel Models for Meta-Analysis." In Multilevel Modelling: Methodological Advances, Issues, and Applications, eds. Steven P. Reise and Naihua Duan, pp. 90-111. Mahawah, NJ: Lawrence Erlbaum.

Hox, Joop J., Edith D. De Leeuw, and Ger Snijkers. 1998. "Fighting Nonresponse in Telephone Interviews; Successful Interviewer Tactics.” In Nonresponse in Survey Research. Zuma Spezial Band 4, eds. A. Koch and R. Porst, pp. 173-85. Mannheim: ZUMA.

Iredell H., T. Shaw, P. Howatt, R. James, and J. Granich. 2004. "Introductory Postcards: Do They Increase Response Rate in a Telephone Survey of Older Persons?" Health Education Research 19(2):159-64.

Khursid, Anwer, and Hardeo Sahai. 1995. "A Bibliography of Telephone Survey Methodology." Journal of Official Statistics 11(3):325-67.

Lavrakas, Paul J. 1993. Telephone Survey Methods. Sampling, Selection, and Supervision. 2nd ed. Newbury Park, CA: Sage.

Lensvelt-Mulders, Gerty J. L. M., Joop J. Hox, Peter G. M. Van der Heijden, and Cora J. M. Maas. 2005. "Meta Analysis of Randomized Response Research: 35 Years of Validation." Sociological Methods and Research 33(3):319-48.

Link, Michael W. 2004. Behavioral Risk Factor Surveillance System. Report of Findings from Advance Letter Response Rate Experiment: Report of the US Centers for Disease Control and Prevention, Division of Adult and Community Health, NCCDPHP Behavioral Surveillance Branch.

Link, Michael W., and Ali Mokdad. 2005. "Advance Letters as a Means of Improving Respondent Cooperation in Random Digit Dial Studies. A Multistate Experiment." Public Opinion Quarterly 69(4):572-87.

Lipsey, Mark W., and David B. Wilson. 2001. Practical Meta-Analysis. Thousands Oaks: Sage. 
Luppes, Martin. 1995. “A Content Analysis of Advance Letters from Expenditure Surveys of Seven Countries.” Journal of Official Statistics 11(4):461-80.

Mann, Christopher B. 2005a. "Do Advance Letters Improve Preelection Forecast Accuracy?" Public Opinion Quarterly 69(4):561-71.

Mann, Christopher B. 2005b. "Prenotification Letters." In Polling America: An Encycplopedia of Public Opinion, eds. Samuel J. Best and Benjamin Radcliff, pp. 556-71. Westport, CT: Greenwood Press.

Massey, James T., Dan O’Connor, and Karol Krotki. 1997. "Response Rates in Random Digit Dialing (RDD) Telephone Surveys." In Proceedings on the Section on Survey Research Methods of the American Statistical Association, pp. 707-12. Alexandria, VA: American Statistical Association.

Nathan, Gad. 2001. "Telesurvey Methodologies for Household Surveys: A Review and Some Thoughts for the Future." Survey Methodology 27(1):7-31.

Oksenberg, Lois, and Charles Cannell. 1988. "Effects of Interviewer Vocal Characteristics on Nonresponse." In Telephone Survey Methodology, eds. Robert M. Groves, Paul P. Biemer, Lars E. Lyberg, James T. Massey, William L. Nicholls, II, and Joseph Waksberg, pp. 257-69. New York: Wiley.

Parsons, Jennifer, Linda Owens, and Wes Skogan. 2002. "Using Advance Letters in RDD Surveys: Results of Two Experiments." Survey Research Newsletter 33(1):1-2.

Pondman, Lisette M. 1998. The Influence of the Interviewer on the Refusal Rate in Telephone Surveys. Ph.D. dissertation, Vrijre Universiteit, Amsterdam.

Raudenbush, Stephen W., and Anthony S. Bryk. 2002. Hierarchical Linear Modeling. Thousands Oaks: Sage.

Selden, Catherine Roos. 1992. "Meta-Analysis. January 1980 Through December 1992." Current Bibliographies in Medicine 92-13. Available at http://www.nlm.nih.gov/archive/ 20040830/pubs/cbm/metaanal.html (accessed January 2006).

Singer, Eleanor. 2002. "The Use of Incentives to Reduce Nonresponse in Households Surveys." In Survey Nonresponse, eds. Robert M. Groves, Don Dillman, John L. Eltinge, and Roderick J. A. Little, pp. 163-78. New York: Wiley.

Singer, Eleanor, Nancy Gebler, Trivellore Raghunathan, John VanHoewyk, and Katherine A. McGonagle. 1999. "The Effect of Incentives in Interviewer-Mediated Survey.” Journal of Official Statistics 15(2):217-30.

Singer, Eleanor, John Van Hoewyk, and Mary P. Maher. 2000. "Experiments with Incentives in Telephone Surveys.” Public Opinion Quarterly 64(2):171-88.

Snow, Robert E., Joames E. Prather, and John D. Hutcheson, Jr. 1986. "Program Evaluating Using a Follow-Up Telephone Survey. The Effect of Prior Letter.” Evaluation Review 10(1):85-94.

Steeh, Charlotte, Nicole Kirgis, Brian Cannon, and Jeff DeWitt. 2001. "Are They Really as Bad as They Seem? Nonresponse Rates at the End of the Twentieth Century." Journal of Official Statistics 17(2):227-47.

Tabachnick, Barbara G., and Linda S. Fidell. 2001. Using Multivariate Statistics. 4th ed. Boston: Allyn and Bacon.

Traugott, Michael W., Robert M. Groves, and James M. Lepkowski. 1987. "Using Dual Frame Designs to Reduce Nonresponse in Telephone Surveys.” Public Opinion Quarterly 51(4):52239.

White, Amanda, Jean Martin, Nikki Bennett, and Stephanie Freeth. 1998. "Improving Advance Letters for Major Government Surveys." In Nonresponse in Survey Research. Zuma Spezial Band 4, eds. A. Koch, and R. Porst, pp. 151-71. Mannheim: ZUMA. 